Vol.16, No. 61, October, 2021, 1122-1134

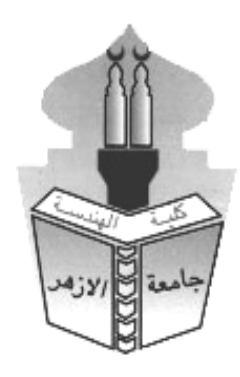

\title{
PERFORMANCE OF DOUBLY FED INDUCTION GENERATOR DRIVEN BY WIND ENERGY AT CONSTANT STATOR POWER AND CURRENT
}

\author{
M. Hussein Agamy ${ }^{1}$, Fathi M. Ellythi ${ }^{2}$, Adel S. Nada ${ }^{2}$, Amr Refky ${ }^{2}$ \\ ${ }^{1}$ Electrical Engineer, Faculty of Engineering, Al-Azhar University, Cairo, Egypt. \\ ${ }^{2}$ Electrical Engineering Deaprtment, Faculty of Engineering, Al-Azhar University, Cairo, Egypt. \\ *Corresponding Author E-mail:eng.mo.hussein@yahoo.com \\ Received : 5 July 2021 Accepted: 6 September 2021
}

\begin{abstract}
This paper discusses the performance of a wind-driven doubly-fed induction generator when connected to the grid. The stator is directly connected to the grid, while the rotor side connection happens via a back-to-back converter. The performance and the steady-state analysis of the Doubly Fed Induction Generator (DFIG) when running at constant stator power and when running at constant stator current will be discussed. Laboratory experiments are performed using a testing bench for the Lucas-Nülle wind power system and the results are analyzed using Lucas-Nülle WindSim software. DFIG analysis and laboratory experiment performance were performed for two different cases; the first case is when DFIG is running at a speed lower than the synchronous speed and the second case is when DFIG is running at a speed above the synchronous speed. In both cases, the values of rotor voltage, stator current, rotor current, and the total generated power from the stator and rotor for DFIG are calculated from the analysis using MATLAB file (m-file) and compared with the practical results.
\end{abstract}

KEYWORDS: Wind energy, DFIG, constant power operation, synchronous speed.

List of symbols:

\begin{tabular}{|l|l|l|}
\hline$X_{\sigma s}$ stator leakage reactance & $V s$ stator voltage & $I_{r}^{\prime}$ referred rotor current \\
\hline$X_{\sigma r}^{\prime}$ rotor referred leakage reactance & $P S$ stator power & $V_{s}$ stator voltage \\
\hline$Z_{r}^{\prime}$ referred rotor impedance & $P_{r}$ rotor power & $V_{r}^{\prime}$ referred rotor voltage \\
\hline
\end{tabular}




$$
\begin{aligned}
& \text { اداء المحرك ثنائي التغذية المنقاد بواسطة طاقة الرياح عند توليد طاقة كهربية ثابتة من الجزء الثابت } \\
& \text { محمد حسين عجمي1، فتحي محروس الليثي2، عادل سعد ندا2، عمرو رفقي عبد الوهاب2 } \\
& \text { 1 1مهندس كهرباء، كلية الهندسة، جامعة الازهر ، القاهرة، مصر } \\
& \text { 2ققم الهندسة الكهربية، كلية الهندسة، جامعة الاز هر، القاهرة ، مصر } \\
& \text { E-mail eng_mo.hussein@yahoo.com البريد الاليكتروني للباحث الرئبسى: }
\end{aligned}
$$

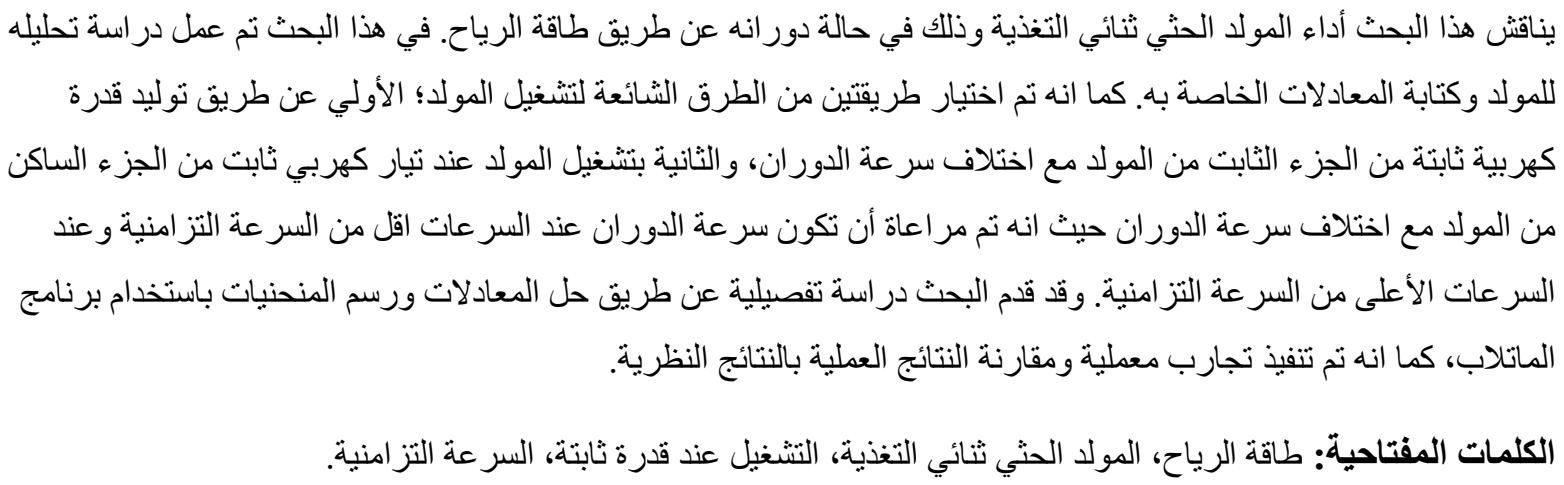

\section{INTRODUCTION}

Wind energy is one of the most promising rapidly growing renewable energy sources in the world. This energy is inexhaustible, clean, and does not create greenhouse gases [1]. Wind turbines usually use DFIG due to its advantages such as it can maintain the amplitude and frequency of the output voltage at a constant value, regardless of the wind speed or the speed of the turbine rotor [2-4]. The DFIG has two outputs: one from the stator and the other from the rotor. The main advantage of DFIG is that the rotor side output represents only (20-25\%) of the total system power [5-7], so the power electronic components handle only a small portion of the generator power. This reduces the acquisition costs and the losses in power electronics devices. The quality of the generated power is also improved by limiting the harmonics and voltage fluctuations [8]. Generally, the stator output is connected directly to the network, but the rotor output is connected via a back-to-back converter [9-12]. The back-to-back converter consists of two converters; Rotor-Side Converter (RSC) and Grid-Side Converter (GSC). The GSC is used for keeping the dc-link voltage constant, while the RSC is used to control the rotor voltage of the DFIG and the power factor at the stator terminals [13]. In the fixed pitch angle of the wind turbine, DFIG can be operated in many different ways, which may be through constantly referred rotor voltage operation, constant stator power operation, constant current stator operation, and operation in two different ways. Many research papers had discussed the performance of DFIG using control methods like Field Oriented Control (FOC) or Direct Power Control (DPC) [4-7]. But this paper does not discuss the control methods of DFIG. It presents theatrically the steady-state analysis and the performance of DFIG at constant stator power and constant stator current and in the laboratory using Lucas-Nülle wind power system. In addition, it compared the theoretical and practical results to provide a full perception of DFIG and its operation modes. The paper writes the equations, draws and explains the curves of power, current, and voltage, and shows how to control the DFIG through the back-to-back converter. 
The paper discusses the steady-state analysis of DFIG in Section 2. Section 3 presents the performance of DFIG when operating at constant stator power, while performance at constant stator current is presented in Section 4. Experimental work at constant power is presented in Section 5.

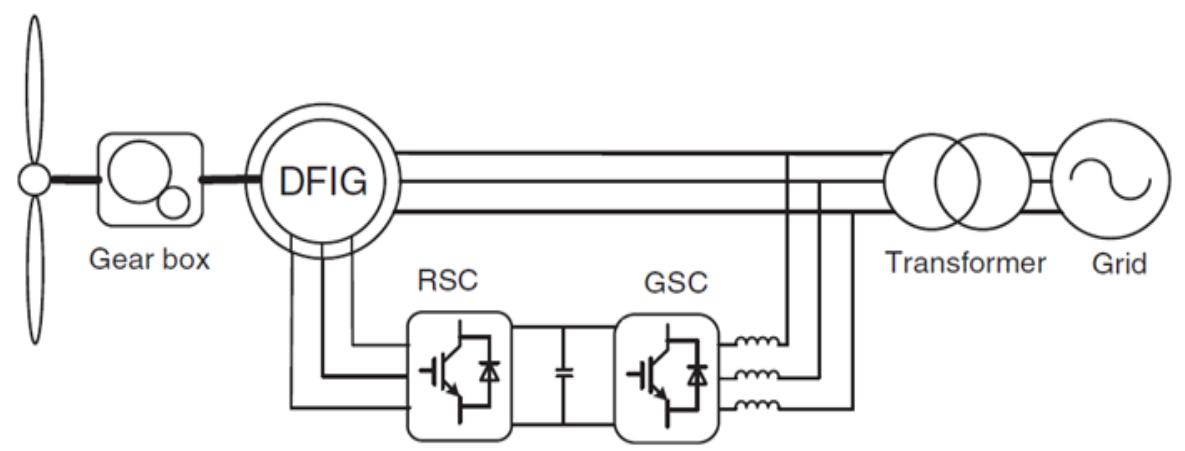

Fig. 1: Variable-speed wind turbine and a doubly-fed induction generator

\section{STEADY-STATE ANALYSIS}

The steady-state behavior of the electrical system is represented through a direct current mathematical model. This model is based on the following assumptions:

i- Linear magnetic circuit for DFIM is assumed.

ii- Mechanical and core losses for DFIM are ignored.

iii- Only fundamental components are taken into account.

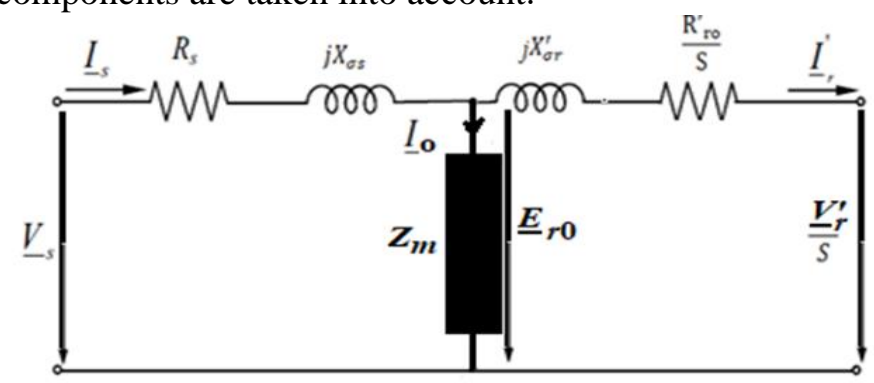

Fig. 2: DIFM equivalent circuit

Figure 2 shows the equivalent circuit of the induction machine with the stator and rotor, each one is connected to an alternating voltage source with appropriate frequency.

The mesh equations for the stator current $I_{s}$, and the referred rotor current $I_{r}^{\prime}$ in the above equivalent circuit are given by:

$Z_{s} I_{s}+Z_{m}\left(I_{s}-I_{r}^{\prime}\right)=Z_{s s} I_{s}-Z_{m} I_{r}^{\prime}=V_{s}$

$Z_{r}^{\prime} \quad I_{r}^{\prime}-Z_{m}\left(I_{s}-I_{r}^{\prime}\right)=Z_{r r}^{\prime} I_{r}^{\prime}-Z_{m} I_{s}=\frac{-{ }^{-} \underline{\prime} r}{S}$

The stator impedance $Z_{s}$ and the referred rotor impedance $Z_{r}^{\prime}$ are given by:

$Z_{s}=R_{s}+j X_{\sigma s}$

$Z_{r}^{\prime}=\frac{R_{r o}^{\prime}}{S}+j X_{\sigma r}^{\prime}$

$Z_{s s}=Z_{s}+Z_{m}$

$Z_{r r}^{\prime}=Z_{r}^{\prime}+Z_{m}$

Equations (1) and (2) can be written in the following matrix form: 
Performance of Doubly Fed Induction Generator Driven By Wind Energy at Constant Stator Power And Current

$\left[\begin{array}{c}V_{s} \\ \frac{-V_{r}^{\prime}}{S}\end{array}\right]=\left[\begin{array}{cc}Z_{s s} & -Z_{m} \\ -Z_{m} & Z_{r r}^{\prime}\end{array}\right] *\left[\begin{array}{c}\frac{I_{s}}{I_{r}^{\prime}}\end{array}\right]$

The above matrix form can be solved for any slip value for $I_{s}$ and $I_{r}^{\prime}$, the solution is:

$\left[\begin{array}{c}\underline{I_{s}} \\ \underline{I_{r}^{\prime}}\end{array}\right]=\frac{1}{\underline{D}}\left[\begin{array}{cc}Z_{r r}^{\prime} & Z_{m} \\ Z_{m} & Z_{S S}\end{array}\right] *\left[\begin{array}{c}V_{S} \\ \underline{-V_{r}^{\prime}} \\ S\end{array}\right]$

Where the determinant $D$ is:

$\underline{D}=Z_{s s} Z_{r r}^{\prime}-Z_{m}^{2}$

From the later matrix equation, the following is obtained:

$\underline{I_{S}}=\frac{Z_{r r}^{\prime}}{\underline{D}} \underline{V_{s}}+\frac{Z_{m}}{\underline{D}} \frac{-V_{r}^{\prime}}{\bar{S}}=\underline{V_{s}}\left[\frac{Z_{r r}^{\prime}}{Z_{s s} Z_{r r}-Z_{m}^{2}}-\frac{Z_{m}}{Z_{s s} Z_{r r}-Z_{m}^{2}} \stackrel{a}{\bar{S}}\right]$

$\underline{I_{r}^{\prime}}=\frac{Z_{m}}{\underline{D}} \underline{V_{s}}+\frac{Z_{S S}}{\underline{D}} \frac{-V_{r}^{\prime}}{S}=\underline{V_{s}}\left[\frac{Z_{m}}{Z_{s s} Z_{r r}-Z_{m}^{2}}-\frac{Z_{S S}}{Z_{s S} Z_{r r}-Z_{m}^{2}} \frac{a}{S}\right]$

$\because \underline{I_{0}}=\underline{I_{s}}-\underline{I_{r}^{\prime}}$

$\therefore \underline{I_{0}}=\underline{V_{s}}\left[\frac{Z_{r r}^{\prime}-Z_{m}}{Z_{s s} Z_{r r}-Z_{m}^{2}}+\frac{Z_{s s}-Z_{m}}{Z_{s s} Z_{r r}-Z_{m}^{2}} \frac{a}{s}\right]$

where:

$a=\frac{V_{r}^{\prime}}{\underline{V_{s}}}$

\section{CONSTANT STATOR POWER ANALYSIS}

To keep the stator power value constant as the speed changes, this is possible within a specific range that is determined according to the performance of the machine parameters.

$P_{\text {generation }}=P_{s}+P_{r}$

From equation (11), with changing the speed, the total generation value at constant stator power $\left(P_{s}\right)$ changes with the value of rotor power $\left(P_{r}\right)$.

If DFIG works at constant stator power, the stator voltage can't be changed because it works according to the grid voltage, so it has all the time a constant value, in addition, the real part of the stator current has a constant value.

The real part of stator current is calculated from:

$$
I_{S} \cos (\varnothing)=\frac{P_{S}}{3 V_{S}}
$$

From the above, the real part from equation (6) has a constant value and it is equal to the real part of the stator current.

$I_{S} \cos (\varnothing)=\operatorname{real}\left[\underline{V_{s}}\left(\frac{Z_{r r}}{Z_{S S} Z \prime_{r r}-Z_{m}^{2}}-\frac{Z_{m}}{Z_{S S} Z_{r r}-Z_{m}^{2}} \stackrel{a}{=}\right)\right]$

With $D$ equals to:

$\underline{D}=Z_{s s} Z_{r r}^{\prime}-Z_{m}^{2}=\left(R_{s}+j X_{\sigma s}+j X_{m}\right)\left(\frac{R_{r o}^{\prime}}{s}+j X_{\sigma r}^{\prime}+j X_{m}\right)+X_{m}^{2}$ 
Performance of Doubly Fed Induction Generator Driven By Wind Energy at Constant Stator Power And Current

$\underline{D}=\left(R_{s}+j X_{s}\right)\left(\frac{R_{r o}^{\prime}}{S}+j X_{r}^{\prime}\right)+X_{m}^{2}$

where $X_{s}=X_{\sigma s}+X_{m}$

And $\quad X_{r}^{\prime}=X_{\sigma r}^{\prime}+X_{m}$

$\underline{D}=R_{s} \frac{R_{r o}^{\prime}}{S}+j R_{s} X_{r}^{\prime}+j \frac{R_{r o}^{\prime}}{S} X_{s}-X_{s} X_{r}^{\prime}+X_{m}^{2}$

$\underline{D}=D_{R}+j D_{i m}=\left(R_{s} \frac{R_{r o}^{\prime}}{S}+X_{m}^{2}-X_{S} X_{r}^{\prime}\right)+j\left(R_{s} X_{r}^{\prime}+\frac{R_{r o}^{\prime}}{S} X_{s}\right)$

From the stator current equation the following equations are obtained:

$\underline{I_{S}}=\underline{V_{S}}\left(\frac{\frac{R_{r o}^{\prime}}{S}+j X_{r}^{\prime}}{D_{R}+j D_{i m}}-\frac{j X_{m}}{D_{R}+j D_{i m}} \frac{a}{S}\right)$

$\underline{I_{S}}=\underline{V_{S}}\left(\frac{\left(D_{R}-j D_{i m}\right)\left(\frac{R_{r o}^{\prime}}{S}+j X_{r}^{\prime}\right)}{D_{R}^{2}+D_{i m}^{2}}-\frac{j X_{m}\left(D_{R}-j D_{i m}\right)}{D_{R}^{2}+D_{i m}^{2}} \frac{a}{S}\right)$

$\underline{I_{S}}=\underline{V_{S}}\left[\left(\frac{\left(D_{R} \frac{R_{r o}^{\prime}}{S}+X_{r}^{\prime} D_{i m g}\right)}{D_{R}^{2}+D_{i m}^{2}}-\frac{X_{m} D_{i m}}{D_{R}^{2}+D_{i m}^{2}} \frac{a}{\underline{S}}\right)-j\left(\frac{\left(D_{i m} \frac{R_{r o}^{\prime}}{S}-D_{R} X_{r}^{\prime}\right)}{D_{R}^{2}+D_{i m}^{2}}+\frac{X_{m} D_{R}}{D_{R}^{2}+D_{i m}^{2}} \frac{a}{S}\right)\right]$

From equation (13), it obtains:

$I_{S} \cos (\varnothing)=V_{S}\left(\frac{\left(D_{R} \frac{R_{r o}^{\prime}}{S}+X_{r}^{\prime} D_{i m g}\right)}{D_{R}^{2}+D_{i m}^{2}}-\frac{X_{m} D_{i m}}{D_{R}^{2}+D_{i m}^{2}} \frac{a}{S}\right)$

Returning to the equations for the stator and rotor currents to get their values by substituting the rotor voltage in the stator current equation (6), and the rotor current in equation (7), then:

$\underline{I_{s}}=\frac{Z_{r r}}{\underline{D}} \underline{V_{s}}+\frac{Z_{m}}{\underline{D}} \frac{\underline{\underline{V_{r}^{\prime}}}}{S}$

$\underline{I_{r}^{\prime}}=\frac{Z_{m}}{\underline{D}} \underline{V_{s}}+\frac{Z_{s s}}{\underline{D}} \frac{-V_{r}^{\prime}}{S}$

The stator and rotor powers equal:

$P_{s}=\operatorname{Real}\left[3 \underline{V}_{s} \underline{I}_{s} *\right]$

$P_{r}=\operatorname{Real}\left[-3 \underline{V_{r}^{\prime}}{\underline{I_{r}^{\prime}}}^{\prime}\right]$

The performance is drawn at constant stator power $(160 \mathrm{~W})$, where the curves are drawn at the speed ( 0.8 to 1.3 ) from the synchronous speed using MATLAB simulation (m file). The DFIG output curves such as (rotor voltage curve, stator current, rotor current, stator, and rotor power curves) are drawn. All curves of the tested DFIG whose parameters are calculated from parameters identification tests (No-load test, locked rotor test, and DC test) are given in the following table.

Table 1: Parameters of DFIM

DFIM, a 4-pole, 3-phase $0.8 \mathrm{~kW}, 400 \mathrm{~V}, 2 \mathrm{~A}, \mathrm{Y}$-connected, $50 \mathrm{~Hz}$, slip ring induction machine

\begin{tabular}{|l|l|l|l}
\hline$R_{S}=5.71 \Omega$ & Transformation ratio $=3.41$ & $X_{m}=180 \Omega$ & $R_{e+h}=1195 \Omega$ \\
\hline
\end{tabular}


Performance of Doubly Fed Induction Generator Driven By Wind Energy at Constant Stator Power And Current \begin{tabular}{|l|l|l|l|l|}
\hline$X_{S}=198 \Omega$ & $V_{\text {stator }}=231 \mathrm{~V}$ & $X_{r}^{\prime}=198 \Omega$ & $V_{\text {base }}=231 \mathrm{~V}$ & $I_{\text {base }}=2 \mathrm{~A}$ \\
\hline
\end{tabular}

The sequence of obtaining the performance curves of the DFIG system is shown in Figure 3, which gives the flowchart of this sequence.

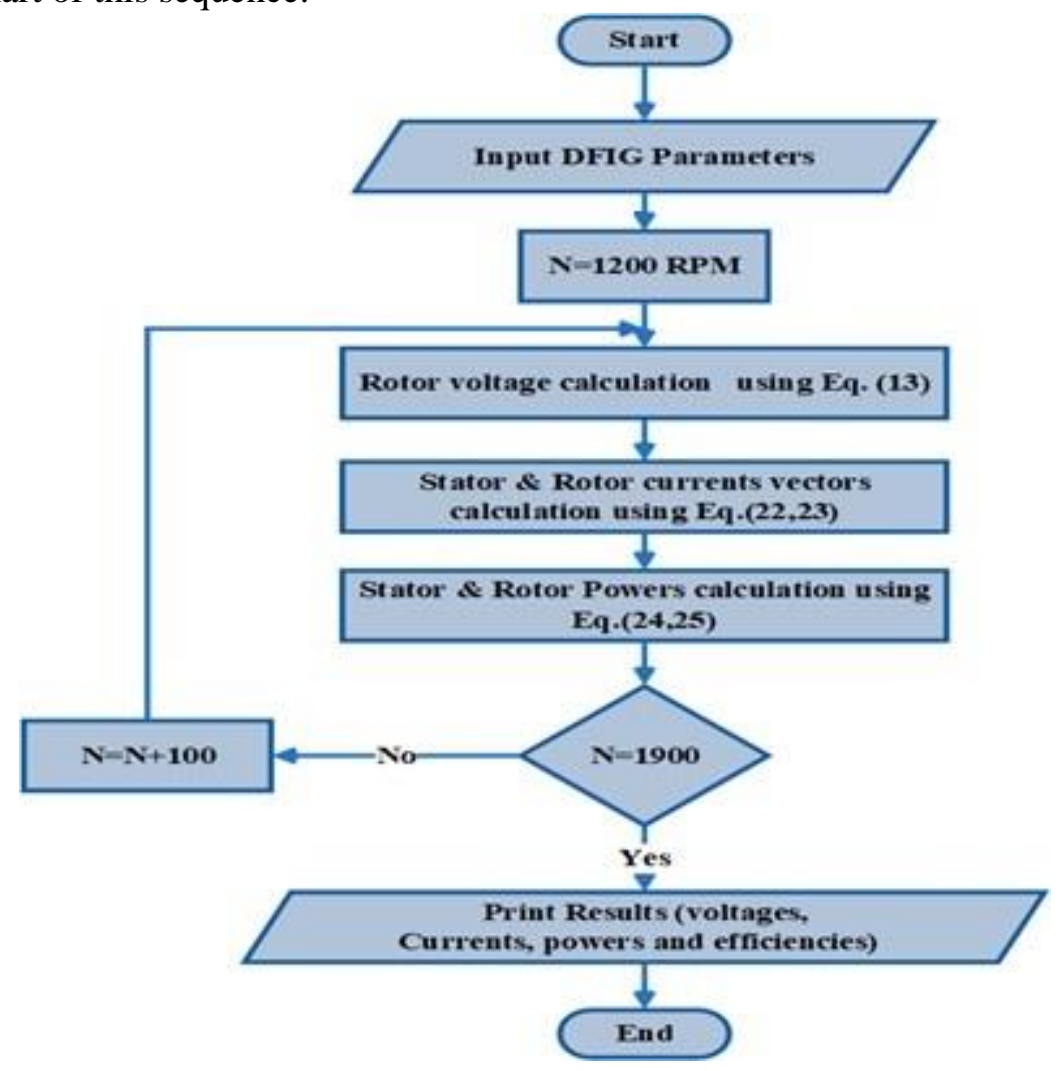

Fig. 3: program flowchart

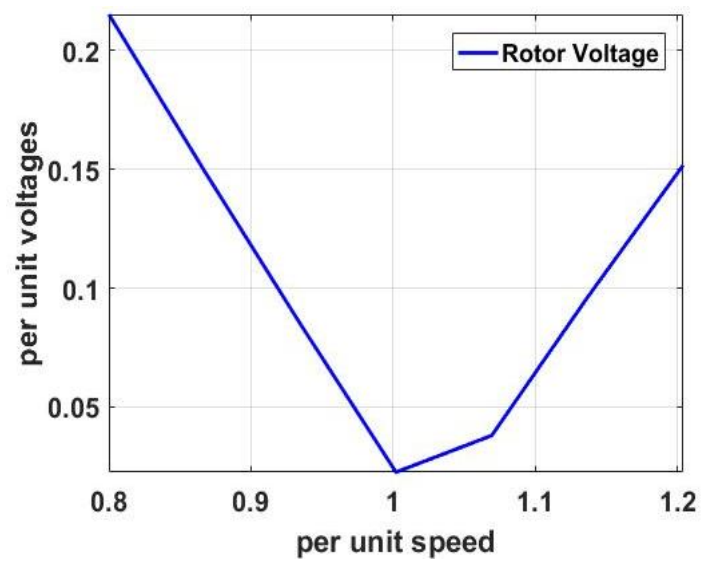

Fig. 4: per unit rotor voltage versus per unit speed at constant stator power

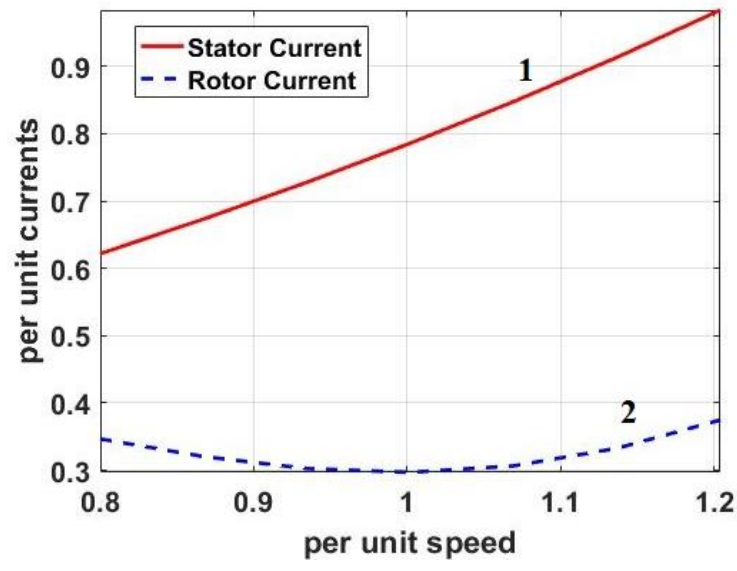

Fig. 5: per unit currents versus per unit speed at constant stator power 


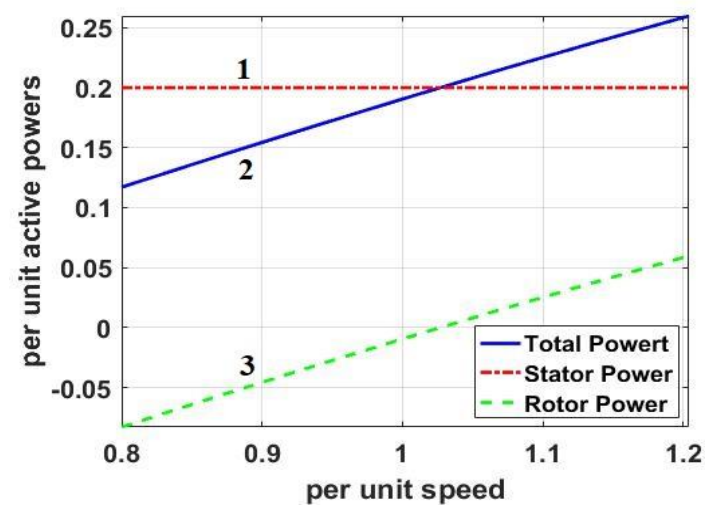

Fig. 6: per unit active powers versus per unit speed at constant stator power

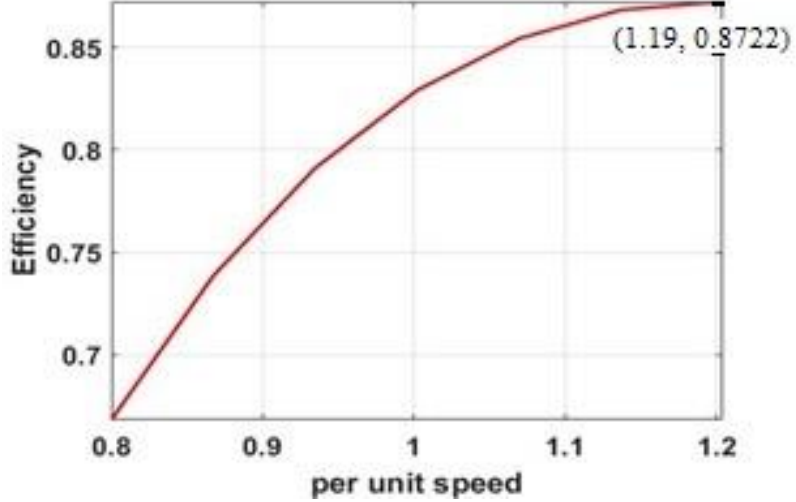

Fig. 7: Efficiency versus per unit speed at constant stator power

As shown in Figure 4, the rotor voltage has positive values in the speed under synchronous speed. This means that the rotor voltage is in phase with the stator voltage and is reduced to zero and turns into negative values at the speed rang over synchronous speed. This means that the rotor voltage in this case is in phase opposite to the stator voltage.

From Figure 5 the value of rotor current (curve no.2) is reduced to reach its minimum value at the synchronous speed and begins to increase in the opposite direction Whereas, although the real part of the stator current does not change, the imaginary part changes with the change of the speed. So the stator current (curve no.1) is slightly increased even the value of the current is greater than the rated value. This means that this must be taken into account when running DFIG at constant stator power so as not to cause the generator windings to burn out.

As shown in Figure 6, the stator power has a constant value all the time. In addition, the rotor power depends on the speed or (the slip). It means that the rotor power has positive values when the speed is under synchronous, which means that the DFIG feeds the power to the grid from the stator but it takes power from the grid from the rotor. The rotor power has negative values when the speed exceeds synchronous speed (curve no. 2).

This means that DFIG will feed energy into the grid from both sides when wind speeds are over the synchronous speed by a certain value.

As shown in Figure 7, the maximum value of theoretical efficiency is (0.8722) at per unit speed $(1.19)$

\section{CONSTANT STATOR CURRENT ANALYSIS}

To keep the stator current value constant as the speed changes, this is possible within a specific speed range. The operation of DFIG at constant stator current means that the absolute value of stator current is constant all the operation time. From the stator current equation (20):

$\left|I_{S}\right|=\sqrt{V_{S}^{2}\left(\frac{\left(D_{R} \frac{R_{r o}^{\prime}}{S}+X_{r}^{\prime} D_{i m g}\right)}{D_{R}^{2}+D_{i m}^{2}}-\frac{X_{m} D_{i m}}{D_{R}^{2}+D_{i m}^{2}} \frac{a}{\underline{S}}\right)^{2}+V_{S}^{2}\left(\frac{\left(D_{i m} \frac{R_{r o}^{\prime}}{S}-D_{R} X_{r}^{\prime}\right)}{D_{R}^{2}+D_{i m}^{2}}+\frac{X_{m} D_{R}}{D_{R}^{2}+D_{i m}^{2}} \frac{a}{\bar{S}}\right)^{2}}$

Because the stator and rotor voltages are real values, the stator voltage is a constant value and the absolute of the stator current has a constant value, so the rotor voltage value can be obtained from the above equation.

Returning to the current equations for the stator and rotor to get their values by substituting the rotor voltage in the stator current equation (22), the rotor current in equation (23), stator and rotor power 
from equations $(24,25)$ the DFIG output curves such as; rotor voltage curve, stator, and rotor current, and powers are drawn.

As shown in Figure 8, the rotor voltage has positive values for speed under synchronous speed. It means that the rotor voltage is in phase with the stator voltage. The rotor voltage values are reduced to reach the zero value at a speed higher than the synchronous speed by a small value. The rotor voltage is in phase opposition with stator voltage and has negative values for speeds higher than synchronous speed.

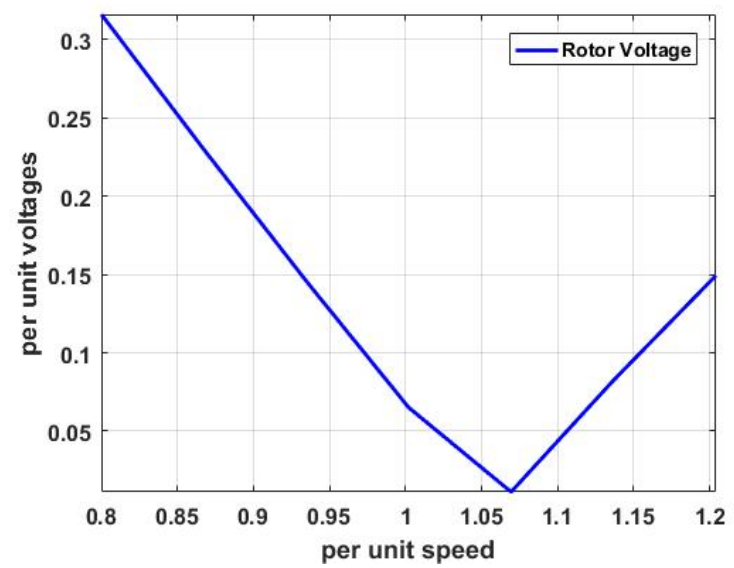

Fig. 8: per unit rotor voltage versus per unit speed at constant stator power

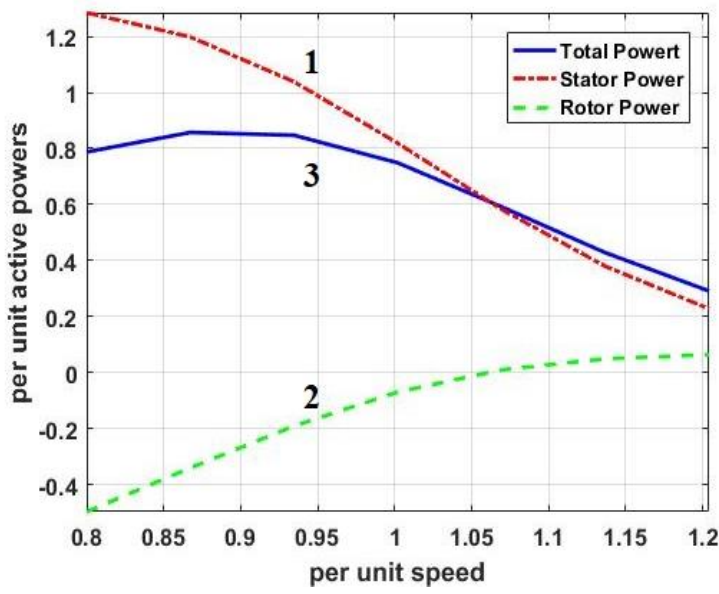

Fig. 10: per unit active powers versus per unit speed at constant stator power

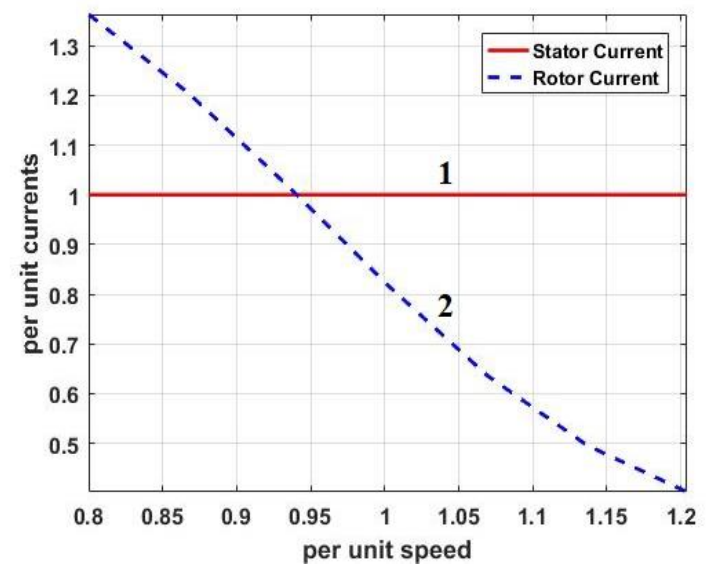

Fig. 9: per unit currents versus per unit speed at constant stator power

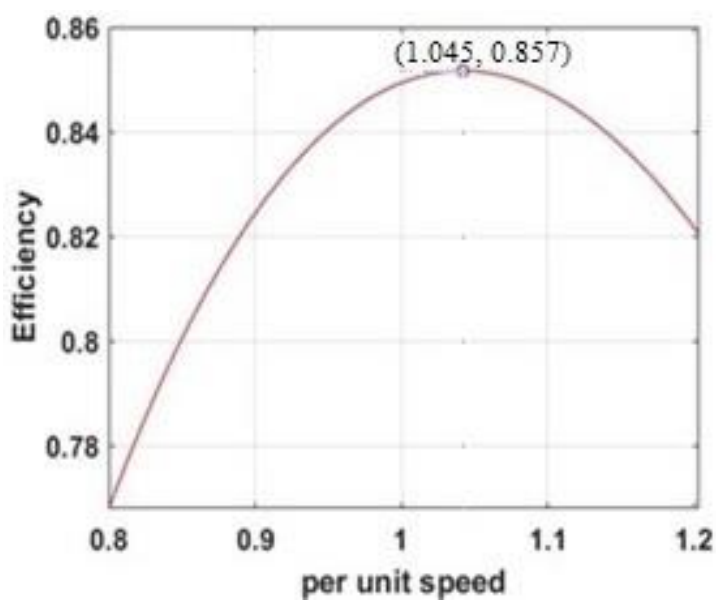

Fig. 11: Efficiency versus per unit speed at constant stator power

In this operation method, the absolute stator current is constant at its rated value (curve no.1). The absolute rotor current value is inversely proportional to the speed. This means that as much as the speed of the turbine is high, the value of the rotor current is decreased as shown in Figure 9.

From Figure 10 the rotor power (curve no.3) behaves like rotor voltages. It has positive values at speeds below the synchronous speed and its values are reduced to zero at speed above the synchronous speed by a small value. This means that the DFIG feeds the power to the grid from the stator but it takes power from the grid from the rotor. When the speed of DFIG exceeds a synchronous speed by a certain value, the rotor power is converted from positive to negative values. This means DFIG supplies power from both sides to the grid. The stator power (curve no.1) is decreased in the case of constant current operation with increasing speed, and the total power (curve no.2) is the summation of rotor and stator powers. 
Performance of Doubly Fed Induction Generator Driven By Wind Energy at Constant Stator Power And Current

As shown in Figure 11, the maximum value of theoretical efficiency is (0.857) at per unit speed (1.045)

\section{EXPERIMENTAL WORK}

Lucas-Nülle DFIG wind turbines describe the design and function of modern wind power plants. The control of variable-speed wind turbines is studied using a doubly-fed asynchronous generator as an example. Wind can be emulated realistically with a servo-machine test stand and "WindSim" software [15]. In this test, the setpoint for a stator power is $160 \mathrm{~W}$. The rotor power is computed theoretically from equation (24) and the actual reading is taken from the controller measurement device. The experiment is done in the speed range from $1200 \mathrm{rpm}$ to $1900 \mathrm{rpm}$ because the controller can cover this range and in this range, the constant stator power can be maintained.

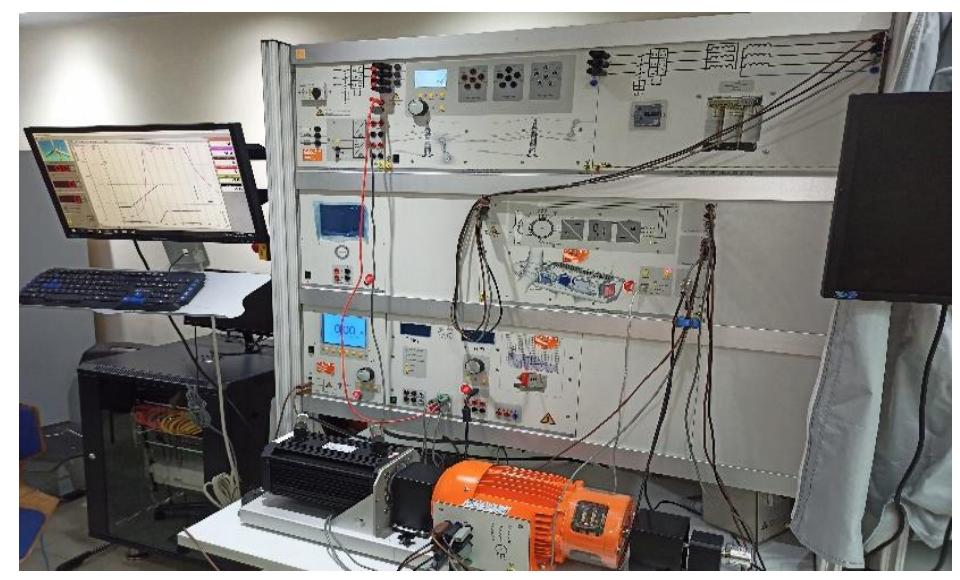

Fig. 12: Testing bench for Lucas-Nülle wind power system

The double-feed induction generator used in practical work is the same as the one in the simulation and its parameters are the same as those shown in Table $\mathbf{1 .}$

As shown in Figures 12 and 13 Lucas-Nülle wind power system consists of:

1- Doubly-fed induction generator (DFIG)

2- Servo motor to simulate the wind power

3- Three-phase isolating transformer for a wind power plant

4- Incremental position encoder to measure the machine speed

5- Controller for a wind power plant's doubly-fed induction generator

6- Power supply for electric machine

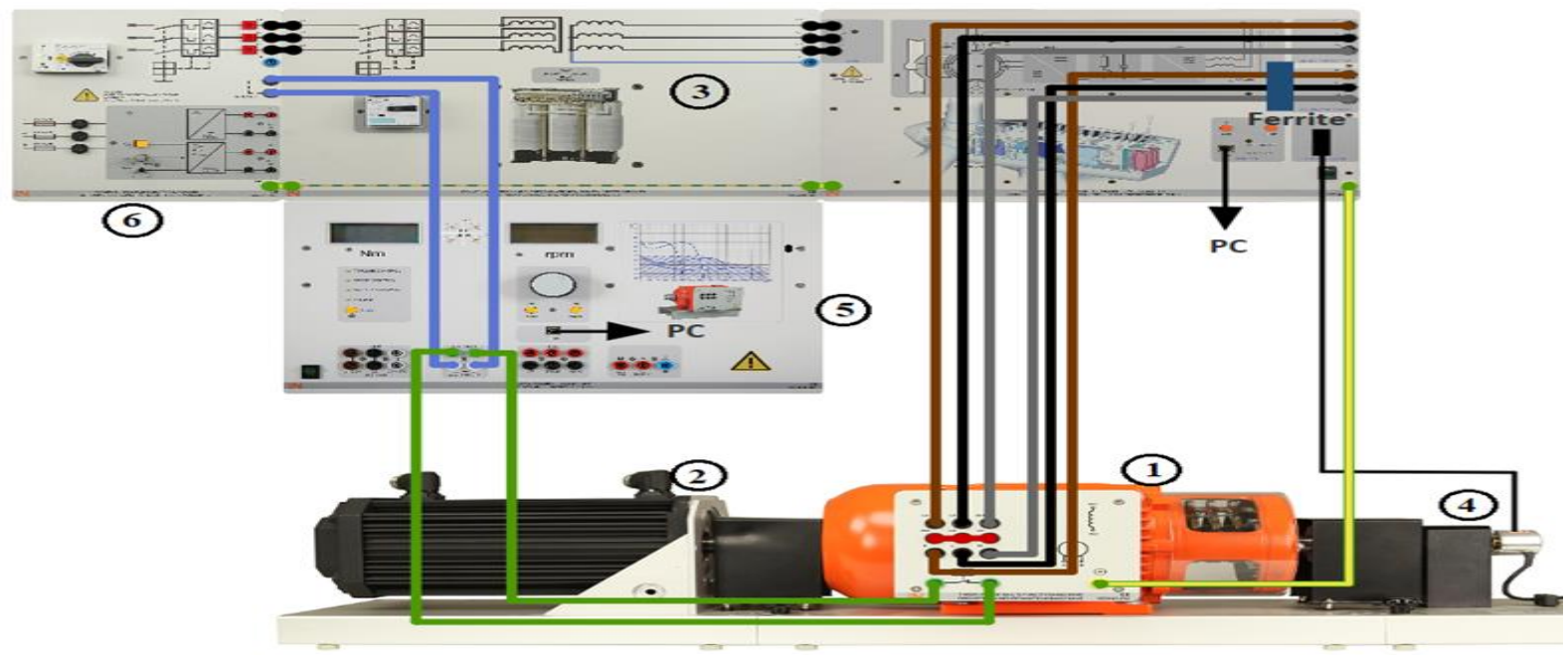


Performance of Doubly Fed Induction Generator Driven By Wind Energy at Constant Stator Power And Current

Fig. 13: Connection diagram for DFIG

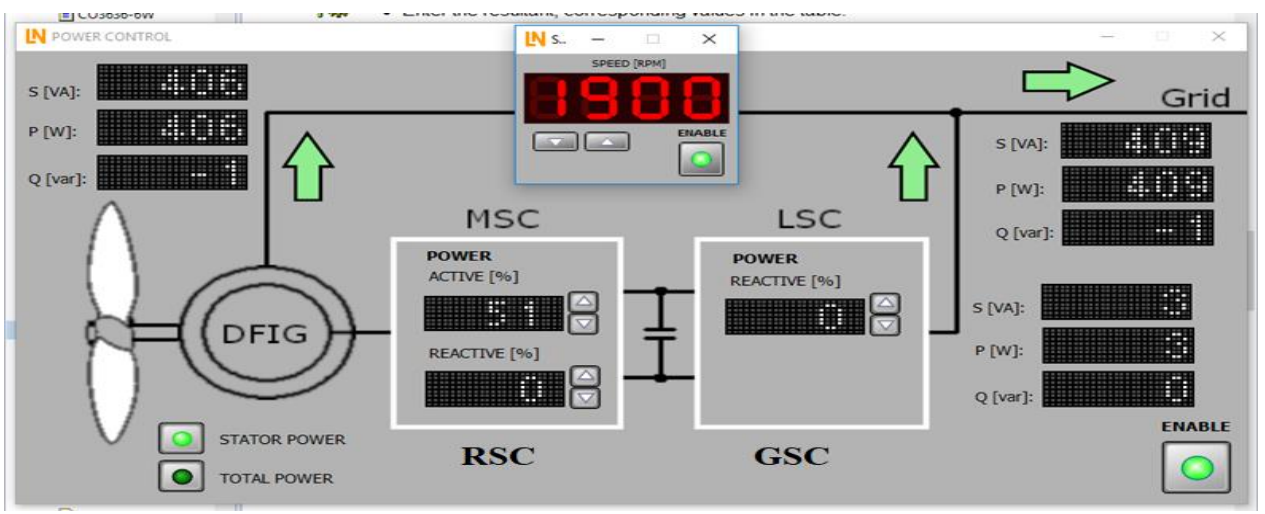

Fig. 14: Testing window for Lucas-Nülle wind power system

\subsection{Constant Power Laboratory Test}

The results of constant power operation test are indicated in the Table 2:

Table 2: Recorded Readings from the Laboratory Test

\begin{tabular}{|c|c|c|c|c|c|c|c|c|c|c|c|c|}
\hline Speed (rpm) & $\mathbf{1 2 0 0}$ & $\mathbf{1 2 6 0}$ & $\mathbf{1 3 0 7}$ & $\mathbf{1 3 6 2}$ & $\mathbf{1 4 0 2}$ & $\mathbf{1 4 6 7}$ & $\mathbf{1 5 0 6}$ & $\mathbf{1 6 0 8}$ & $\mathbf{1 7 0 8}$ & $\mathbf{1 7 5 2}$ & $\mathbf{1 8 5 4}$ & $\mathbf{1 9 0 0}$ \\
\hline $\begin{array}{c}\text { Stator Power } \\
(\mathbf{W})\end{array}$ & 158 & 159 & 155 & 158 & 159 & 157 & 165 & 159 & 162 & 160 & 157 & 157 \\
\hline $\begin{array}{c}\text { Rotor Power } \\
(\mathbf{W})\end{array}$ & -124 & -115 & -106 & -101 & -96 & -86 & -78 & -69 & -59 & -54 & -46 & -40 \\
\hline $\begin{array}{c}\text { Total Power } \\
(\mathbf{W})\end{array}$ & 34 & 43 & 48 & 56 & 63 & 71 & 87 & 90 & 102 & 105 & 111 & 117 \\
\hline $\begin{array}{c}\text { Stator Current } \\
(\mathbf{A})\end{array}$ & 0.329 & 0.321 & 0.349 & 0.336 & 0.341 & 0.339 & 0.343 & 0.335 & 0.339 & 0.327 & 0.32 & 0.314 \\
\hline $\begin{array}{c}\text { Rotor Current } \\
(\mathbf{A})\end{array}$ & 0.25 & 0.23 & 0.21 & 0.20 & 0.19 & 0.17 & 0.15 & 0.14 & 0.12 & 0.11 & 0.09 & 0.08 \\
\hline
\end{tabular}

As shown in Figure 15 the stator current oscillates around a certain value (curve no.1). While the rotor current decreases with increasing speed (curve no.2).
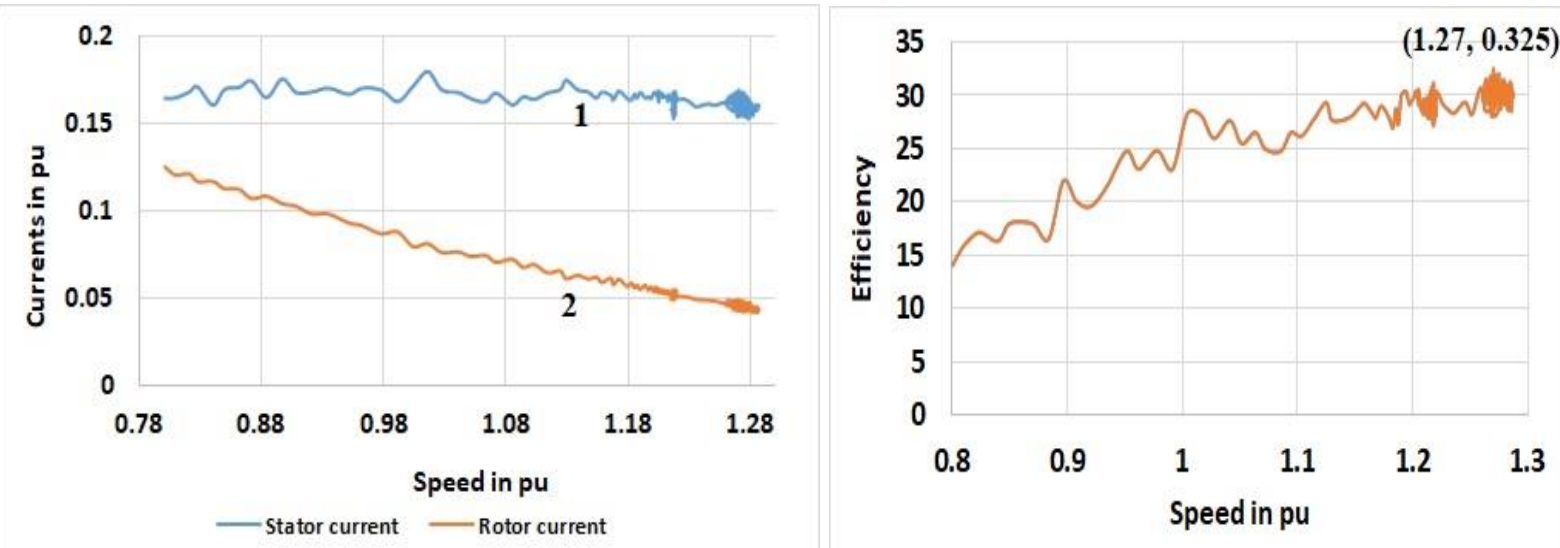
Fig. 15: per unit currents versus per unit speed at constant stator power
Fig. 16: Efficiency versus per unit speed at constant stator power

When comparing Figures 5, 9, and 15, it finds that the rotor current is still decreasing even after the speed exceeds the synchronization speed. This means that the current is still passing in the same direction (from the network to the generator) and its direction is not changed because of large losses during excitation of the generator and switching operations by the generator's controller. This leads to that the rotor continues to consume power from the network even after the generator speed exceeds the synchronous speed.

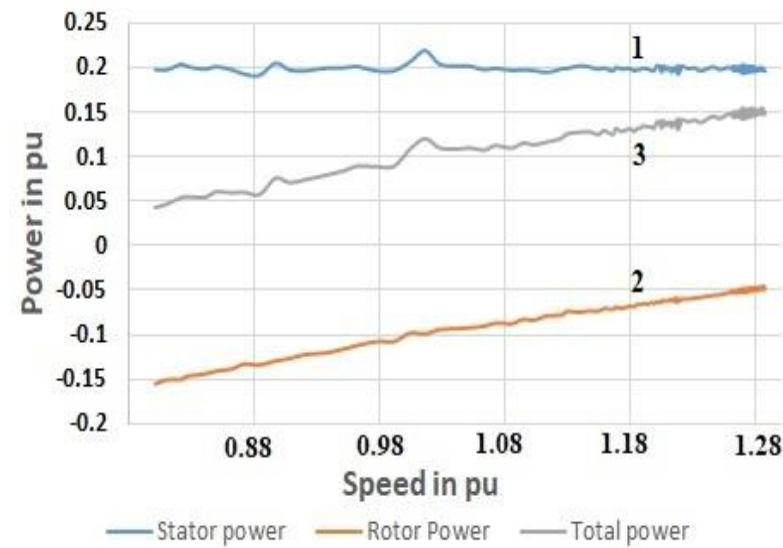

Fig. 17: per unit active powers versus per unit speed

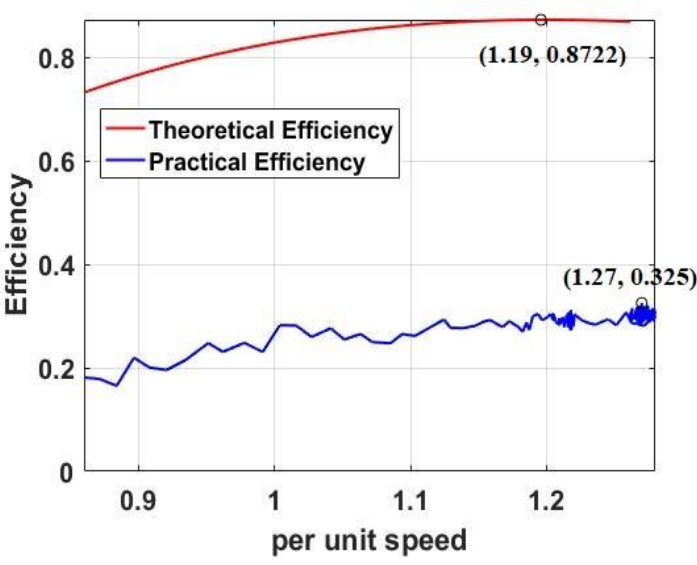

Fig. 18: Efficiency versus per unit speed

From Figure 17, the stator power is constant at $(160 \mathrm{~W})$ and the rotor power has negative values when the speed is less than the synchronous speed. This means that the rotor is consuming power from the grid. By increasing the speed, the rotor power begins to shift from negative to positive values. This means that the rotor pumps power into the network. As the speed rises and the active power of the stator remains constant, the power consumption of the rotor decreases. As a result, the total active power rises. The rotor can also supply power to the network during super synchronous operation.

Comparing Figures 6, 10, and 17, it is found that, as with current, the rotor continues to consume power because the power value remains negative even after the speed exceeds the synchronization speed due to large losses during generator excitation and shunt operations by the generator controller.

As shown in Figure 18, the maximum efficiency in the practical work is $(0.3250)$ at per unit speed (1.27). There are some ripples in the efficiency curve at about speed (1900 rpm) due to the fluctuation of output power caused by running the generator at this speed for a long time.

It is clear from Figures $\mathbf{1 1}$ and $\mathbf{1 8}$ that efficiency in experimental work is lower than efficiency in theoretical work. The difference between the two values is due to losses due to negligence in theoretical work, but in practical work, other types of losses greatly affect the operating efficiency. Loss due to generator excitation and switching operations by the generator control unit and negligible losses in Section 2. These losses are not constant and depend on the generator drive parameters and the efficiency of the control unit.

\section{CONCLUSION}

This paper presented the Lucas-Nülle wind power system and used it to perform appropriate laboratory experiments and the results are compared with the theoretical results. From the practical work, it is found that the performance of the generator is somewhat different from the theoretical work, as a result of neglected losses. It is also clear that the method of constant stator power operation is not the optimal mode of operation. Because the current can be higher than the rated current if the DFIG 
speed or stator power is increased. Therefore, limits must be set for the speed as well as for the force drawn from the stator. In addition, switching at high speeds to constant stator current operating mode can be a good solution to avoid overcurrent.

\section{REFERENCES}

[1] Akrama Khan, et al., "Doubly Fed Induction Generator Open Stator Synchronized Control during Unbalanced Grid Voltage Condition”, MDPI, Rourkela Odisha, Energies, Vol.13, pp.3155, (2020).

[2] Mansouri FatimaZohra, Bendjebbar Mokhtar, Mazari Benyounes, "Sliding mode performance controlapplied to a DFIG system for a wind energy production", International Journal of Electrical and Computer Engineering (IJECE), Vol.10, No.6, pp. 6139 6152, (December-2020).

[3] Shwe Hlaing, "Basic Concepts of Doubly Fed Induction Generator Driven by Wind Energy Conversion System", International Journal of Scientific Engineering and Technology Research, Vol.03, No.15, pp. 3242-3246, (2014)

[4] M. Hussein Agam, Fathe M. Allythi, Adel S. Nada, "Proposed synchronization circuits connecting wind driven DFIG to the public grid", International Journal of Power Electronics and Drive System (IJPEDS), Vol. 12, No. 1, pp. 151 159 ISSN: 2088-8694, Mar (2021).

[5] A. Ramkumar, "Performance Analysis of Doubly Fed Induction Generator Based Wind Energy Conversion Systems", Department of Electrical and Electronics Engineering Kalasalingam University, India, June (2014).

[6] Y. Djeriri, A. Meroufel, A. Massoum, Z. Boudjema, "Direct Power Control of A Doubly Fed Induction Generator Based Wind Energy Conversion Systems Including A Storage Unit", Journal of Electrical Engineering, Vol.14, pp. 196-204, March (2014).

[7] Jihen Arbi, et al., "Direct Virtual Torque Control for Doubly Fed Induction Generator Grid Connection", IEEE Transactions on Industrial Electronics, Vol.56, pp. 4163- 4173, No. 10, OCTOBER (2009).

[8] Subramanian Chandrasekaran, "Grid Connected Doubly Fed Induction Generator Based Wind Turbine under LVRT", Department of Electric, Electronic and Information Engineering, University of Bologna, Italy, (2014).

[9] B. Rabelo and W. Hofmann. "Power Flow Optimisation and Grid Integration of Wind Turbines with the Doubly-Fed Induction Generator", IEEE 36th Power Electronics Specialists Conference, pages 2930-2936, (2005).

[10] Habib Benbouhenni, "Comparison study between seven-level SVPWM and two-level SVPWM strategy in direct vector control of a DFIG-based wind energy conversion systems", International Journal of Applied Power Engineering (IJAPE), Vol.9, No.1, pp. 12 21, (April-2020).

[11] Rishabh Dev Shukla, Ramesh Kumer Tripathi, "Speed-sensorless Voltage \& Frequency Control in Autonomous DFIG based Wind Energy Systems", Australasian Universities Power Engineering Conference, AUPEC 2014, Curtin University, Perth, Australia, 28 September - 1 October (2014).

[12] Raghav Dhanuka, "Modelling of Doubly Fed Induction Generator Based Wind Turbine", National Institute of Technology, Rourkela Odisha, India, May (2013). 
Performance of Doubly Fed Induction Generator Driven By Wind Energy at Constant Stator Power And Current

[13] Ali Ghasemi, Mohammad Hossein Refan, Parviz Amiri, "Enhancing the performance of grid synchronization in DFIG-based wind turbine under unbalanced grid conditions", Springer-Verlag GmbH Germany, part of Springer Nature, (2020).

[14] Petersson A., "Analysis, Modeling and Control of Doubly-Fed Induction Generators for wind Turbines”, PhD Thesis, Chalmers University of Technology, Göteborg, Sweden, (2005).

[15] "Lucas-Nülle wind power plant with DFIG”, https://www.lucas-nuelle.us/2768/apg/13194/EWG1-Wind-power-plant-with-DFIG.htm. 